\title{
Study of Rational and Irrational Prescribing in Different Government and Private Health Care Centres of Punjab
}

Bashir T*, M Zeeshan Zafar, M Ahsan, M Asim, M Abu-Huzaifa

Department of Pharmacy, Graduates College of Pharmacy, University of Sargodha, Pakistan

\begin{abstract}
Introduction: Rational prescribing is the prescribing of drug by physician in the right way, right drug, right dose and right time to the right person through the right route of administration. On the other hand irrational prescribing is blanket term which is a combination of no drug need, drug abuse and misuse, use of polypharmacy and use of unsafe drugs.

Methodology: This was cross sectional study and was conducted at District Head Quarters of Gujranwala, Hafiz Abad, Wazirabad and Okara from July-August 2017. The case histories of 400 patients were scrutinized thoroughly on the basis of questionnaire filling related to rational and irrational guidelines and compare our results with international standards. We used a Microsoft Excel 2013 for to evaluate our results.

Results: A total of 400 patients were studied. Pharmacoeconomics analysis shows that in 177 patients' drug therapy is rational while in 223 patients' medications prescribed were irrational.

Conclusion: It is the need of the hour that the mutual relationship among the medical health care professionals is necessary like doctors, pharmacists, nurses, nutritionist, physiotherapist and other technicians to provide optimum and rational drug therapy to the patients.
\end{abstract}

Keywords: Drug Therapy; Rational Therapy; Irrational therapy

\section{Introduction}

\section{Causes of irrational drug use}

- Irrational prescribing practices of doctors.

- Dispensing by pharmacists and drug sellers.

- Drug pricing policies and promotional activities of the pharmaceutical industry.

- Lack of information, education and communication on rational drug use to providers and consumers.

- Lack of effective control and regulatory mechanisms on drug use.

- Lack of political will and leadership to promote rational use.

Medicines play an important role in healthcare delivery and when used properly, can help cure diseases, relieve symptoms and alleviate patient suffering. Nonetheless, irrational use of medicines remains a major issue facing most health systems across the world. The World Health Organization (WHO) estimates that more than half of all medicines are inappropriately prescribed, dispensed, or sold. Additionally, around $50 \%$ of patients fail to take their medicines correctly.

\section{Methodology}

\section{Study design}

It was a cross sectional study. It was carried out at Government district headquarters of Gujranwala, Wazirabad, Okara and different private clinics was also included in our study from above mentioned cities.

\section{Patients size}

It included 200 patients from private clinics and 200 patients from Govt. Hospitals. If we explain number of patients on the basis of cities then we concluded that we take 100 patients from each city [1-6].

\section{Study duration}

The period of study was 20 July 2017 to 18 Aug 2017.

\section{Inclusion and exclusion criteria}

This study was restricted to patients of Diabetes Mellitus, Hepatitis, Ischemic Heart Disease, Malaria, Hypertension and Tuberculosis. Only these patients were added in our study other all were eliminated. All other patients with these diseases were excluded from the study and total of 400 patients were enrolled in the study.

\section{Ethics approval}

Our study was approved by research committee of University of Sargodha and gave us permission to collect data and evaluate it on the basis of different variables [7-14].

\section{Method of sampling}

The Pharmacological data of patients was collected from ward history sheets. Mainly our study was based on prescription based as which we concluded from this which percentage of patients receives rational medication and which receive irrational medications. We collected prescription from clinics and hospitals and investigated them on the basis of few questions which was we prepared for our study.

*Corresponding author: Tahir Bashir, Department of Pharmacy, Graduates College of Pharmacy, University of Sargodha, Pakistan, Tel: 923056427027; E-mail: Tahirbashir364@gmail.com

Received: November 27, 2017; Accepted January 06, 2018; Published January 13 2018

Citation: Bashir T, Zafar MZ, Ahsan M, Asim M, Abu-Huzaifa M (2018) Study of Rational and Irrational Prescribing in Different Government and Private Health Care Centres of Punjab. J Pharmacovigil 6: 250. doi:10.4172/2329-6887.1000250

Copyright: ( 2018 Bashir T, et al. This is an open-access article distributed under the terms of the Creative Commons Attribution License, which permits unrestricted use, distribution, and reproduction in any medium, provided the original author and source are credited. 


\section{Results}

\section{Evaluation of prescription on the basis of health care units}

First of all, we evaluated our research study on the basis of health care units (Clinics and Govt. Hospitals). In this we took 200 patients from each health care unit. In clinics which patients we took from them 86 was male and 114 were females, on the other hand in [1420] hospitals 95 and 105 males and females respectively. If we see rational and irrational prescribing in them then we concluded that in clinics $63 \%$ prescribing is rational and $37 \%$ was irrational prescribing. In government hospitals $25.5 \%$ and $74.5 \%$ rational and irrational prescribing respectively was seen. We can show these results from Table 1 and Figure 1.

\section{Evaluation on the basis of cities}

Here, we evaluated our research study on the basis of cities which was Gujranwala, Okara, Wazirabad and Hafiz Abad. In this we took 100 patients from each city. From each city we took 50 patients from clinics and 50 from government hospitals. If we see results on the basis of rational and irrational [21-25] then see that rational prescribing was 48, 41, 45 and 43 in Gujranwala, Okara and Wazirabad and in Hafiz Abad respectively and irrational prescribing was 52, 59, 55 and 57 in Gujranwala, Okara and Wazirabad and in Hafiz Abad respectively (Table 2).

\section{Prescriptions evaluation on the basis of economic status of patients}

In this we evaluate patients on the basis of their economic status

\begin{tabular}{|c|c|c|c|c|c|c|c|}
\hline Health care & Number of \\
units & patients & \multicolumn{2}{|c|}{ Gender } & \multicolumn{2}{|c|}{ Rational } & \multicolumn{2}{|c|}{ Irrational } \\
\cline { 3 - 8 } & Male & Female & Total & Percentage & Total & Percentage \\
\hline $\begin{array}{c}\text { Clinics } \\
\text { (Private) }\end{array}$ & 200 & 86 & 114 & 126 & $63 \%$ & 74 & $37 \%$ \\
\hline Hospitals & 200 & 95 & 105 & 51 & $25.50 \%$ & 149 & $74.50 \%$ \\
\hline
\end{tabular}

Table 1: Evaluation of prescription on the basis of health care units.

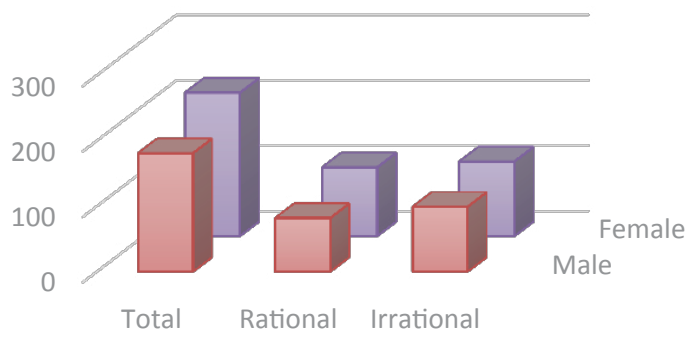

$\square$ Male $\square$ Female

Figure 1: Evaluation of results on the basis of sex.

\begin{tabular}{|c|c|c|c|c|c|}
\multirow{2}{*}{ Cities } & \multirow{2}{*}{$\begin{array}{c}\text { Number of } \\
\text { patients }\end{array}$} & $\begin{array}{c}\text { Health care units } \\
\text { Clinics } \\
\text { (Private) }\end{array}$ & Hospitals & Rational & Irrational \\
\hline Gujranwala & 100 & 50 & 50 & 48 & 52 \\
\hline Okara & 100 & 50 & 50 & 41 & 59 \\
\hline Wazirabad & 100 & 50 & 50 & 45 & 55 \\
\hline Hafiz Abad & 100 & 50 & 50 & 43 & 57 \\
\hline Total & 400 & 200 & 200 & $177(44.25 \%)$ & $223(75 \%)$ \\
\hline
\end{tabular}

\section{Patients/Prescription evaluation on the basis of Economic Status}

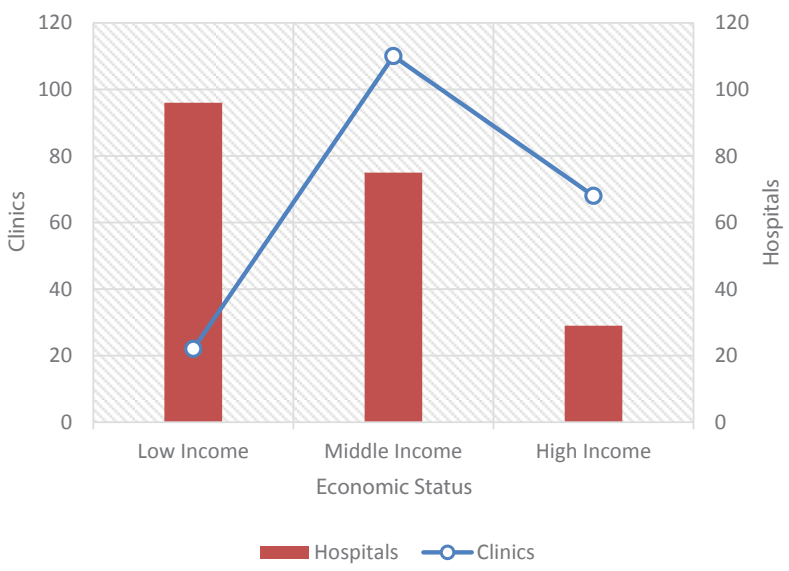

Figure 2: Evaluation of prescriptions on the basis of pharmacoeconomics.

and this find by verbal communication with patients and set a criteria for this that if a patient income in less than 20000 then this lies in low income, 20000-50000 lies in middle income and more than $50 \mathrm{~K}$ income patient was in high income status. From this we evaluated that mostly low income and middle income persons preferred government hospitals which was economically suitable for them. By our results we find that patients who preferred clinics were 22, 110 and 68 belonged from low income, middle income and high income respectively. On the other hand patients which preferred hospitals were 96, 75 and 29 of low income, middle income and high income respectively (Figure 2).

\section{Discussion}

Prescriptions evaluation for pharmacoeconomics study is done on the basis of cities and health care units including hospitals and clinics to check the rational and irrational prescribing. Prescriptions including both male and female and the ratio of female in different health setup is greater than male. The results shown that the rational prescribing is done in private clinics (63\%) but in hospitals there is no proper setup for rational prescribing but some hospitals done $(25.5 \%)$. If we see overall result of rational and irrational prescribing then this is $44.25 \%$ and $55.75 \%$ respectively. From our study we also evaluated that as we know Pakistan is a middle income country so there is not well established health care units are available which provided a good health. When we study the economic status of patients and complete therapy cost then therapy cost in clinics is greater than hospitals so peoples moves towards hospitals but the problem is irrational prescribing. A brief explanation of pharmacoeconomics in the curriculum of health care professionals i.e. MBBS, Pharm-D and nursing will prove fruitful in future for increasing coordination between health care professionals and ultimately for rational therapy of medications with respect to pharmacoeconomics. Simply rational prescribing of medicines provides health and wealth and in a country like Pakistan where there are limited resources of economics and finance it is the need of hour that we should move toward the rational prescribing. If the rate of rational prescribing will greater than the irrational prescribing then this will support to the patient in his health and it will also be cost effective. The aim of rational prescribing is to minimize the overall cost of therapy. 
Citation: Bashir T, Zafar MZ, Ahsan M, Asim M, Abu-Huzaifa M (2018) Study of Rational and Irrational Prescribing in Different Government and Private Health Care Centres of Punjab. J Pharmacovigil 6: 250. doi:10.4172/2329-6887.1000250

Page 3 of 3

\section{Conclusion}

The irrational use and non-prescription sale of medicines will not only promote health problems but can also be linked with pronounced adverse events including drug adverse effects, high cost and complications. Although the practice of non-prescription sale/ Irrational use of medicines of drugs is inappropriate and unethical. Changing the practice of nonprescription sale and irrational prescribing requires a sustained restoration of the Pakistani Health System in a bid to make medical care available to people and promote education of the population and physician for the rational use of medicines.

\section{References}

1. Harika J (2012) An overview of pharmacoeconomics and outcomes research. Int J LifeSc Bt \& Pharm Res 1: 6.

2. Goreck PK (2017) Availability and pricing new medicines in ireland: Reflections and reform. PharmacoEconomics 35: 981-987.

3. Rubio-Rodriguez D, Blanco SDD, Perez M, Rubio-Terres C (2017) Costeffectiveness of drug treatments for advanced melanoma: A systematic literature review. PharmacoEconomics 35: 879-893.

4. Dummer R, Hauschild A, Lindenblatt N, Pentheroudakis G, Keilholz U (2015) ESMO Guidelines Committee. Cutaneous melanoma: ESMO clinical practice guidelines for diagnosis, treatment and follow-up. Ann Oncol 26: v126-v132.

5. Kim BN, Masud MA, Kim Y (2014) Optimal implementation of intervention to control the self-harm epidemic. Osong Public Health Res Perspect 5: 315-323.

6. Khan A, Zaman S (2010) Costs of vaginal delivery and Caesarean section at a tertiary level public hospital in Islamabad, Pakistan. BMC Pregnancy and Childbirth 10: 2.

7. Bhagavathula AS, Sarkar BR, Patel I (2014) Clinical pharmacy practice in developing countries: Focus on India and Pakistan. Arch Pharma Pract 5: 91-94.

8. Zhang W, Li Y, Li Y, Li X, Zhao W, et al. (2015) A cross-sectional analysis of prescription and stakeholder surveys following essential medicine reform in Guangdong Province, China. BMC Health Services Research 15: 98.

9. Kattavenkatesh R, Prabhu MM, Pai KSR, Nandhakumar KK (2015). Pharmacoeconomic Evaluation of Geriatric Diabetics in a Tertiary Care Hospital: A Prospective Study. Value Health 18: A603.

10. Trask LS (2008) Pharmacoeconomics Principle Methods and Applications. In: Posey LM, (ed). Pharmacotherapy-A Pathophysiologic Approach. $8^{\text {th }}$ edn. USA: McGraw Hill, pp: 1-3.
11. Cooke J (2011) Pharmacoeconomics. In: Walker R, Whittlesea $C$ (eds). Clinical Pharmacy and Therapeutics. $5^{\text {th }}$ edn. USA, pp: 91-101.

12. Shargel L, Mutnick AH (2009) Pharmacoeconomics In: Souney PF, Swanon LN (eds) Comprehensive Pharmacy Review. $7^{\text {th }}$ edn. Philedphia: Lipponcott Williams and Wilkins.

13. Sanchez LA (1995) Pharmacoeconomic principles and methods: Conducting pharmacoeconomic evaluations in a hospital setting. Hosp Pharm 30: 412-428.

14. Townsend RJ (1987) Post marketing drug research and development. Drug Intell Clin Pharm 21134-136.

15. Bootman JL, Wertheimer A, Zaske D, Rowland C (1979) Individualizing gentamicin dosage regimens in burn patients with gram-negative septicemia: $A$ cost-benefit analysis. J Pharm Sci 68:267-272.

16. Boyce EG, Umland EM (2001) Sildenafil citrate: A therapeutic update. Clin Ther 23: 2-23.

17. Grausova L, Kromka A, Bacakova L, Potocky S, Vanecek M, et al. (2003) Bone and vascular endothelial cells in cultures on nanocrystalline diamond films. Diamond and Related Materials 17: 1405-1409.

18. Cicero TJ, Inciardi JA, Surratt $\mathrm{H}$ (2007) Trends in the use and abuse of branded and generic extended release oxycodone and fentanyl products in the United States. Drug Alcohol Depend 91: 115-120.

19. Abdelhafiz AH, Wheeldon NM (2003) Use of resources and cost implications of stroke prophylaxis with warfarin for patients with nonvalvular atrial fibrillation. Am J Geriatr Pharmacother 11: 53-60.

20. Mc Ghan W, Rowland CR, Bootman JL (1978) Cost-benefit and costeffectiveness: Methodologies for evaluating innovation pharmaceutical services. Am J Hosp Pharm 35:133-140.

21. Law MG, Maposa P, Steeb DR, Duncan G (2017) Addressing the global need for public health clinical pharmacists through student pharmacist education: A focus on developing nations. IJCP 39: 1141-1144.

22. Patil JS (2015) Clinical pharmacist in indian health care system. J Pharmacovigil 3: e125.

23. Pierson JB, Berridge BR, Brooks MB, Dreher K, Koerner J, et al. (2013) A public-private consortium advances cardiac safety evaluation: Achievements of the HESI Cardiac Safety Technical Committee. JPTM 68: 7-12.

24. Kim HK, Lee M (2016) Factors associated with health services utilization between the years 2010 and 2012 in Korea: Using Andersen's Behavioral model. Osong Public Health Res Perspect 7: 18-25.

25. Acharya J (2016) Are Free Maternity Services Completely Free of Costs? Osong Public Health Res Perspect 7: 26-31. 